\title{
Inclusão social de crianças com paralisia cerebral: óptica dos profissionais de saúde ${ }^{1}$
}

\author{
Inclusion process for children with cerebral palsy: \\ the health professionals perspective
}

\author{
Ticiana Melo de Sá RORIZ² \\ Katia de Sousa AMORIM² \\ Maria Clotilde ROSSETTI-FERREIRA ${ }^{2}$
}

\begin{abstract}
Resumo
O destacado papel dos profissionais de saúde no atendimento de crianças com deficiência levou à investigação de como eles concebem o processo de inclusão dessas crianças. Foram feitas, para tanto, entrevistas com esses profissionais a partir de dois estudos de caso de crianças com paralisia cerebral. Para contextualizar as falas, realizaram-se ainda entrevistas com os familiares. A análise qualitativa baseou-se na rede de significações. Verificou-se que os profissionais trabalham em contextos diversos, com práticas e discursos distintos, marcados pela estrutura e meta das instituições. A atuação dos profissionais é circunscrita, também, pelas características das crianças e da organização familiar. No geral, o olhar e a intervenção junto à criança com deficiência remetem à sua incapacidade geral, usualmente limitando seu processo inclusivo.
\end{abstract}

Unitermos: Paralisia cerebral. Profissionais de saúde. Socialização.

\begin{abstract}
Health professionals have a prominent role in the treatment of children with deficiencies. In view of this prominence, we have investigated how these professionals conceive the inclusion of children with deficiencies. With this object in mind, we conducted interviews with health professionals, based on two case studies of children with cerebral palsy. To put the verbalizations into context, we also interviewed the children's parents. Qualitative analysis was based on the network of meanings. Results show that professionals are used to working within diverse contexts, presenting distinct practices and discourses, which are determined by the institution's structure and aims. In addition, the professionals' work was either constrained by the children's characteristics or by the family organization. The professional's intervention with the child with the deficiency depends on the child's overall incapacity, usually tending to constrain the process of inclusion.
\end{abstract}

Uniterms: Cerebral palsy. Professional of health. Socialization.

$\operatorname{ctur}$

1 Artigo elaborado a partir de dissertação de T.M.S. RORIZ, intitulada "Inclusão social de crianças com paralisia cerebral: óptica dos profissionais de saúde". Universidade de São Paulo, 2005.

2 Universidade de São Paulo, Faculdade de Filosofia, Ciências e Letras de Ribeirão Preto, Centro de Investigações sobre Desenvolvimento Humano e Educação Infantil. Av. Bandeirantes, 3900, Monte Alegre, 14040-901, Ribeirão Preto, SP, Brasil. Correspondência para/Correspondence to: T.M.S. RORIZ. E-mail: $<$ ticianamelo@gmail.com>.

Agradecimentos: a Fundação Cearense de Apoio ao Desenvolvimento Científico e Tecnológico (processo número: 2323), Fundação de Amparo à Pesquisa do Estado de São Paulo (projeto temático) e Conselho Nacional de Desenvolvimento Científico e Tecnológico (projeto universal) pelo financiamento do estudo; aos serviços de saúde e seus profissionais e aos familiares e às crianças que participaram da investigação. 
Nesta última década, de forma crescente, tem-se discutido sobre a inclusão, que trata do respeito às diferenças e à participação igualitária dos cidadãos. Fala-se da inclusão social, digital, cultural, econômica e escolar, dentre outras. No caso de crianças com necessidades especiais, especificamente daquelas com deficiências (físicas, sensoriais e/ou mentais), a inclusão abarca sua participação na sociedade em geral e, em instituições de educação em particular.

Considerando-se a participação social e escolar de crianças com deficiências no Brasil, entende-se que a social tem-se dado de forma muito diversa se considerarmos o conjunto de nossa história. Jannuzzi (2004), numa densa análise da Educação Especial no Brasil, indica a presença de múltiplas vozes, lutas e movimentos, com o entrelaçamento de discursos, intenções pessoais e de grupos particulares, tanto nacional como internacionalmente, cada qual situado em contextos socioeconômicos, históricos e culturais diversos.

Segundo a autora, as políticas e as práticas voltadas às crianças com necessidades especiais se constituíram em estreita relação com questões que dizem respeito à história da infância, da família, da educação, da população, da urbanização, do trabalho, das relações de produção, assim como em relação às políticas e concepções pedagógicas e sobre desenvolvimento. Esses vários elementos envolvidos acabaram por estabelecer limites e possibilidades no interior das quais as pressões e as relações de força produziram resultados com significados complexos.

Esse entrelaçamento, em função dos diferentes tipos de deficiências e das diversas concepções sobre deficiência, competência e função social, teria resultado na construção de diferentes paradigmas com relação ao lugar atribuído a essas crianças. A partir de cada paradigma, seriam então atribuídos e assumidos lugares sociais diversificados em relação a essas crianças com deficiência, com a concretização de diferentes formas de concebê-las e atuar junto a elas.

Tal diversidade de lugares impostos, assumidos e negociados com essas pessoas expressa-se na existência de diferentes termos utilizados para referir-se a elas. Já foram denominadas de anormais, retardadas, imbecis, indisciplinadas, preguiçosas, excepcionais, portadoras de defeitos pedagógicos e portadoras de necessidades especiais (Jannuzzi, 2004). Esses sentidos contribuem para constituir as pessoas, dentro dos diversos grupos sociais, como deficientes/diferentes, incapazes/capazes, impossíveis/possíveis de serem educadas e incluídas.

Como afirma Parmenter (2001), as denominações usadas e as práticas que elas implicam revelam-se importantes na construção da própria realidade social. Dessa maneira, em função dessas significações, em certos momentos históricos, elas poderiam ser mortas ao nascer; fazer parte da rotina de vida da casa ou do trabalho; ser confinadas em asilos para alienados; ou ainda ser educadas em institutos, fundações, escolas especiais, classes especiais ou classes regulares (Jannuzzi, 2004).

O fato de certas concepções existirem nas sociedades na forma de discursos hegemônicos faz com que, por vezes, pareçam estar envoltas em uma uniformidade e coerência. No entanto, uma análise mais crítica desses discursos evidencia múltiplas vozes e contradições. Na verdade, muitos dos diversos sentidos atribuídos às deficiências ao longo da história ainda hoje se fazem presentes, inclusive se confrontando.

Observa-se, portanto, a extrema complexidade da situação, havendo um rol de diversas perspectivas nas formas de identificações e práticas dirigidas às pessoas com necessidades especiais. Ao buscarmos um foco para entender facetas significativas desse processo, consideramos particularmente relevante conhecer como os profissionais de saúde concebem e abordam a inclusão de crianças com necessidades especiais. Tal interesse deveu-se ao fato de que, em função de aspectos que marcam a história e a organização social, esses profissionais representam importantes mediadores (muitas vezes, os primeiros) junto às famílias e às crianças com deficiências.

\section{Profissionais de saúde e inclusão de pessoas com necessidades especiais}

No que diz respeito ao campo da saúde, profissionais médicos ocupam lugar de destaque. São os precursores de muitas das práticas e detentores, até hoje, de importante conhecimento e prestígio junto à população, acabando por exercer um papel dominante entre os profissionais da saúde, sendo bastante valorizados junto aos pacientes e às suas famílias. 
No entanto, apesar de a medicina ser a ciência da saúde mais antiga e a mais consolidada, nestas últimas décadas, várias profissões do campo da saúde foram se especializando, dando origem a práticas distintas. No Brasil, de 1954 a 1984, as profissões de assistente social, psicólogo, fisioterapeuta, terapeuta ocupacional e fonoaudiólogo foram sendo respectivamente regulamentadas. O surgimento desses novos campos de saber e seus discursos vieram contribuir com a alteração do próprio conceito de saúde, que passou a englobar não apenas os estados de morbidez e patologia como também o bem-estar físico, psicológico e social do indivíduo (Spink, 2003).

O contexto de origem de cada profissão e os objetivos de cada uma delas, articulados aos discursos sociais dominantes sobre ser humano, são questões marcantes na prática dos profissionais e nas perspectivas que estabelecem para as pessoas com necessidades especiais. Essas perspectivas se tornam da maior relevância na medida em que reconhecemos o grande valor atribuído pela sociedade ao saber dos profissionais de saúde. O diagnóstico e o prognóstico estabelecidos por esses profissionais contribuem sobremaneira para a circunscrição dos limites e das possibilidades atribuídos à pessoa com necessidades especiais.

No intuito de verificar como a área da saúde está sendo considerada e investigada no que diz respeito à inclusão social e/ou escolar de pessoas com necessidades especiais, foi realizado um levantamento bibliográfico.

A revisão foi feita nas bases de dados MedLine, PsycINFO e Lilacs, compreendendo o período de 1978 a 2003. Foram utilizadas como palavras-chave inclusion and preschool, inclusion and health, inclusion and cerebral palsy, além de inclusão e educação, inclusão e saúde, inclusão e paralisia cerebral. Aqui trataremos das questões mais relevantes dos resultados desse levantamento (Roriz, Amorim \& Rossetti-Ferreira, 2005).

Um ponto significativo da análise é que verificamos que alguns autores indicam a existência, nessa área, de um destaque à intervenção da área de saúde. Tal valorização é referida através do reconhecimento da ênfase sobre a estimulação ativa e intensiva dos profissionais, desconsiderando-se outros agentes e campos de atuação nas atividades diárias (Lebeer \& Rijke, 2003). A figura central, aquele que detém o saber, acaba por ser o profissional da saúde, o especialista. No caso de pessoas com lesões cerebrais, destacam-se principalmente o médico e os profissionais da área de reabilitação.

No entanto, esse lugar de destaque é visto pelos referidos autores (Lebeer \& Rijke, 2003) como requerendo cuidado. Eles evidenciaram que testes realizados apresentam o risco de se tornarem uma "profecia" e que rótulos podem influenciar nos (baixos) desempenhos escolares. Para eles, os limites e as possibilidades relacionados ao processo de desenvolvimento não devem ser indicados a partir de um recorte transversal dado pelos testes, mas sim a partir do complexo ambiente onde a criança está imersa, que é composto por familiares, amigos e profissionais comprometidos.

Rao (2001) também aborda a questão dos rótulos. Para a autora, o foco dos serviços tanto médicos como educacionais está centrado na "deficiência". No entanto, segundo a autora, as famílias sabem como incluir seus filhos, porque conhecem sua capacidade, enxergando-os além da sua deficiência. A autora aponta para a importância de que os programas de reabilitação aproveitem a riqueza dos recursos familiares, contrapondose à sua usual subestimação.

Baker e Donelly (2001) exploraram a influência do ambiente na qualidade de experiências sociais de quatro crianças com síndrome do X frágil. Nesse estudo, evidenciaram que a superproteção dos pais, sempre citada como obstáculo para as experiências sociais, foi vista como consequência da falta de suporte de médicos, terapeutas, amigos e familiares.

Como vemos, os trabalhos citados trazem a importância da relação da família com os profissionais de saúde, mas apontam também à necessidade de se repensar essa relação de maneira diferenciada, entendendo-se que os familiares também têm muito a contribuir com esse processo.

Como síntese da revisão bibliográfica, verificamos que, apesar do destacado lugar que os profissionais de saúde ocupam no cotidiano das crianças com deficiências, no que se refere aos processos de inclusão social, é bastante recente e escassa a investigação direta da ligação desses profissionais com essas práticas. Porém, identificamos que eles estão sendo indiretamente considerados por alguns autores. Essa 
abordagem indireta aponta para a falta de suporte familiar, para a subestimação da família e para a concepção do diagnóstico como profecia de desenvolvimento limitado a essas crianças.

Diante da escassez de estudos empíricos com esse enfoque e, ainda, tendo em vista as implicações das práticas atribuídas e/ou assumidas pelos profissionais de saúde, estabelecemos o objetivo de nosso trabalho, que buscou investigar concepções dos profissionais de saúde sobre inclusão social e escolar de crianças deficientes. A meta foi apreender se esses profissionais concebem contribuir para a inclusão dessas crianças e o modo como esse processo se desenvolve. Como planejamento estratégico do estudo, definimos por apreender a óptica de profissionais de saúde a partir de estudos de caso de crianças com paralisia cerebral.

\section{Método}

O estudo foi desenvolvido a partir de dois estudos de caso (Yin, 2005). Para a condução do estudo, tanto na coleta como na análise dos dados, utilizamos os pressupostos da perspectiva da Rede de Significações (RedSig) (Rossetti-Ferreira, Amorim, Silva \& Carvalho, 2004).

\section{Perspectiva teórico-metodológica da rede de significações}

A RedSig foi elaborada pelo grupo de pesquisa do Centro de Investigações sobre Desenvolvimento Humano e Educação Infantil (CINDEDI), da Faculdade de Filosofia, Ciências e Letras de Ribeirão Preto, da Universidade de São Paulo, como uma ferramenta a ser usada tanto na construção e análise de corpus de pesquisa, como na compreensão dos complexos processos de desenvolvimento humano. Dentro dessa perspectiva, o desenvolvimento é concebido por meio de processos que ocorrem durante todo o ciclo vital, nas e pelas múltiplas interações estabelecidas pelas pessoas em contextos culturalmente organizados e socialmente regulados, nos quais cada pessoa tem componentes pessoais específicos e desempenha um papel ativo.

No caso de crianças com paralisia cerebral, tornam-se constitutivas do seu processo de desenvol- vimento e, mesmo, de sua inclusão social suas particularidades e experiências corporais. Essas experiências são associadas e atravessadas pela forma como a limitação de movimentos é interpretada pelos parceiros de interação, dentro dos contextos socioculturais. A depender das significações, essas características podem ser consideradas como incapacitantes ou não; como tendo potencialidades amplas ou restritas. Assim, as necessidades especiais só podem ser pensadas quando inter-relacionadas aos valores e crenças do grupo social, os quais emergem em ambientes específicos através dos campos interativos que se estabelecem com outras pessoas.

As ações, que se concretizam mediadas por esses campos interativos, estabelecem-se dentro de processos dialógicos intersubjetivos, nos quais cada pessoa tem seu fluxo de comportamentos continuamente delimitados, recortados e interpretados pelo(s) outro(s) e por si próprio, por meio da atribuição de papéis e contrapapéis recíprocos. Esses papéis, contrapapéis e suas significações podem ser aceitos, negados, confrontados, negociados e/ou transformados na interação das pessoas, dentro de contextos específicos.

Os contextos são concebidos como culturalmente organizados e socialmente regulados, guiados por funções e rotinas específicas. Eles se definem e são definidos pelos papéis sociais que as pessoas ali desempenham. No caso das pessoas com deficiência, nem todos os contextos se encontram preparados para acolhê-las. Devido às funções a que se propõem, esses contextos despreparados atribuem, muitas vezes, àquelas pessoas o papel de incompetentes, sem chances de se desenvolverem e de se integrarem às situações e às rotinas. Colocam-nas, assim, numa posição de exclusão, na qual elas têm pouco poder de negociação e de superação dos limites.

As pessoas em interação em contextos específicos são compreendidas como atravessadas e impregnadas por uma matriz sócio-histórica, de natureza semiótica, composta por elementos sociais, econômicos, políticos, históricos e culturais. A matriz não é homogênea, sendo permeada por vários discursos com diferentes pesos e hierarquias de poder em determinada sociedade, cultura e relacionamento (Amorim, 2002).

Para Rossetti-Ferreira, Amorim e Silva (2000), há o entrelaçamento de vários aspectos para cada pessoa, 
em cada momento, em função dos parceiros e dos lugares que frequentam, e das práticas discursivas (Spink, 1999) atribuídas e/ou sendo desempenhadas. Tal entrelaçamento promove, metaforicamente, a estruturação de uma rede, com uma determinada configuração, que atua como um circunscritor da situação, estabelecendo possibilidades e limites aos significados atribuídos à criança, aos seus comportamentos, às ações relacionadas a ela e ao seu desenvolvimento.

Foi a partir dessa perspectiva que o corpus da pesquisa foi construído e analisado.

\section{Participantes}

Antes de detalhar o estudo, mostra-se importante mencionar que o projeto de pesquisa foi aprovado pelo Comitê de Ética em Pesquisa do Hospital das Clínicas de Ribeirão Preto. A pesquisa foi apresentada e discutida com todos os participantes, tendo sido o Termo de Consentimento Livre e Esclarecido assinado por cada um deles. Foi firmado, assim, um compromisso ético. Processo (2565/2002).

Os sujeitos da pesquisa, profissionais de saúde, foram escolhidos a partir da seleção de duas crianças de três anos de idade, com paralisia cerebral. A triagem dessas crianças foi feita a partir de prontuários médicos de serviços de saúde primário e terciário, ambos parte do Sistema Único de Saúde. Definimos como principais critérios para seleção as crianças terem entre três e cinco anos de idade, terem o diagnóstico de paralisia cerebral e serem acompanhadas por diferentes profissionais de saúde, na região de cidade de médio porte do interior de São Paulo. Definidas as crianças, todos os profissionais de saúde que atuavam com elas foram convidados a participar da pesquisa.

Optou-se por trabalhar com os profissionais que acompanhavam crianças atendidas em setores de saúde distintos por acreditarmos que, a partir desses diferentes contextos, poderiam emergir práticas diversas, com diferentes posicionamentos dos profissionais de saúde com relação à situação de inclusão. O que se procurou com esse procedimento não foi comparar os serviços, mas ampliar a possibilidade de apreender múltiplas vozes ligadas a essas situações.

Entende-se que, apesar de o foco central serem as práticas discursivas dos profissionais de saúde, mostrava-se fundamental conhecer as crianças e suas famílias para que pudéssemos entender de quem os profissionais falavam. Para tanto, foram entrevistados os familiares por meio de uma visita domiciliar.

Vale ressaltar que, tendo como pressuposto básico a perspectiva teórico-metodológica da Rede de Significações, a pesquisadora também é considerada como uma participante da pesquisa. O contato com o objeto de investigação a coloca dentro de uma complexa e dinâmica rede de significações, que contribui para estruturar o projeto e canalizar seus recortes e interpretações. Além disso, acredita-se que o que é dito pelo entrevistado é dialogicamente coconstruído com o entrevistador, ganhando sentido na relação situada e contextualizada do setting de entrevista.

Com o objetivo de investigar como os diferentes profissionais de saúde se posicionam e se referem às necessidades especiais das crianças e ao seu processo de inclusão social e escolar, foi feita, individualmente, uma entrevista semiestruturada (roteiro em anexo) com cada um dos profissionais. As entrevistas foram todas gravadas em áudio, à exceção de uma delas, em função do não consentimento de gravação por parte do entrevistado. As entrevistas foram realizadas no próprio ambiente de trabalho dos profissionais, sempre em locais reservados.

Como referido, de modo a uma noção mais próxima e direta da criança referida pelos profissionais de saúde, foi feita uma visita domiciliar, quando foi realizada uma entrevista com os familiares com o intuito de verificar o que eles tinham a falar sobre seu filho e sobre a relação que estabelecem com o(s) serviço(s) de saúde que o atende(m) (Anexos 1 e 2).

Após cada contato com os participantes do estudo (profissionais da saúde, crianças e familiares), foram registradas as impressões e percepções da pesquisadora em notas de campo, onde foram também referidos as possíveis dificuldades enfrentadas e os aspectos positivos do estudo.

As entrevistas feitas com os profissionais e familiares foram transcritas e arquivadas no computador. A partir da sua leitura, rastreamos, em cada entrevista, as percepções e as falas dos profissionais sobre: (1) a criança; (2) a relação familiar; (3) o papel do profissional de saúde; (4) a inclusão social; e (5) a inclusão escolar. Na busca, 
eram considerados tanto adjetivos/qualidades atribuídos a cada um desses tópicos, como ações que os envolviam, direta ou indiretamente, e que estavam carregadas por percepções desses profissionais sobre os assuntos.

Nesse processo, destaca-se a maneira como a criança era vista por cada interlocutor e como eles percebiam que ela era tratada e cuidada. Nesse sentido, buscávamos identificar como os profissionais concebiam a participação da criança nos diferentes contextos sociais. Identificamos ainda o que achavam da colocação ou não da criança na escola regular e quais as perspectivas com relação ao desenvolvimento futuro da criança.

A partir dessa perspectiva, foi separado as falas por temas e por interlocutores com o intuito de verificar a diversidade e a eventual predominância de determinados assuntos. Busca-se, ainda, identificar em que ponto as falas dos diferentes profissionais eram (in)congruentes, negociavam sentidos e/ou sofriam tensões entre si.

\section{Resultados}

Para a apresentação dos resultados, foi feita inicialmente uma explanação de cada caso. Em seguida, trouxe recortes de falas dos profissionais de saúde e as falas dos familiares quando forem pertinentes. Esses recortes compreenderão significados atribuídos à criança, à realidade familiar, às perspectivas futuras e à inclusão social e escolar da criança em foco. Ao término da apresentação de cada caso, será feita uma discussão.

\section{Estudo de caso de Letícia}

No caso de Letícia, foi entrevistado todos os profissionais de saúde envolvidos no seu seguimento, especificamente o neurologista infantil, o fisioterapeuta, o fonoaudiólogo, o psicólogo e o assistente social.

À época da coleta de dados, Letícia tinha três anos e um mês. Com cerca de um ano, foi acometida por uma encefalite, que deixou como sequela uma paralisia cerebral. Ela apresenta uma hemiparesia à esquerda, que representa alteração de tônus mais evidente em um dos hemicorpos (perna e braço do mesmo lado).
Letícia é capaz de permanecer sentada, mas com um equilíbrio instável. Não deambula, locomovendo-se "de gatinhas". É capaz de passar da postura deitada para sentada com facilidade, apoiando-se no lado direito. Quando colocada de pé apoia bem o lado direito, com a perna esquerda permanecendo flexionada. Sua mão esquerda permanece fechada o tempo todo. $\mathrm{Na}$ tentativa de manipular objetos, não consegue, nem mesmo com a mão direita, que também possui incoordenações.

Letícia é uma criança que não tem linguagem oral, comunicando-se por gestos, posturas e expressões faciais. Explora o ambiente com o olhar, não sorri em hora nenhuma na visita, permanecendo com expressão esquiva, sendo ainda bastante arredia ao toque. Parece ter alguma compreensão do que está acontecendo ao seu entorno; por exemplo, choramingou todas as vezes que a mãe teceu reclamações a seu respeito ("dá trabalho para comer", "não era assim! Era linda! Depois, ficou assim!"). Fisicamente, é uma criança bonita, mas pouco cuidada, estando despenteada e aparentando estar suja.

Ela é residente em cidade de pequeno porte do interior do Estado de São Paulo, onde mora com a mãe, a avó, a tia, o irmão mais velho e dois primos. Na visita domiciliar, verificou-se que moram todos em um cômodo único, adaptado no quintal da casa da tia-avó. Percebeu-se pouca higiene, também, na casa e nos familiares. A mãe é analfabeta e a única pessoa da casa que trabalha, recebendo $\mathrm{R} \$ 500,00$ mensais Além desse salário, a família tem um rendimento que vem da aposentadoria por invalidez da criança.

Letícia era atendida, há cerca de um ano, no ambulatório de neurologia infantil de um serviço terciário de saúde da região. Além desse serviço, Letícia é acompanhada por fisioterapeuta, fonoaudióloga, psicóloga e assistente social na Associação de Pais e Amigos dos Excepcionais (APAE) de sua cidade. Ela frequenta a instituição diariamente, fazendo parte da Escola Especial.

Coloca-se a pergunta de como os profissionais de saúde que atendem Letícia concebem a ela e à sua inclusão social e escolar. Para discutir isso é, apresentado, a partir de agora, recortes de fala de alguns interlocutores. Vale dizer que, quando um significado semelhante aparecia nas entrevistas dos diferentes profissionais, de 
modo a não ser repetitivo nessa apresentação, foram selecionados as falas que trouxessem aquele sentido de forma mais clara e objetiva.

No caso dessa criança, quando solicitado que o profissional relatasse como é a Letícia, houve grande dificuldade de descrição. Essa dificuldade de falar diretamente da criança é clara na fala do fisioterapeuta, que indaga se era para responder em termos de "patologia ou de um modo geral" Quando orientado a falar da criança em particular, a dificuldade permanece, pois o fisioterapeuta ora trata dos aspectos em que Letícia "poderia vir a ser trabalhada", ora fala da família. A fala da psicóloga também não indica as características de Letícia, trazendo vagamente o seu percurso de desenvolvimento: "Tá melhorando, assim... Mas, devagar". A assistente social também não consegue falar da criança, remetendo-se à família. Diz ela: "O problema da Letícia é a mãe. Ela vem de um ambiente familiar muito difícil".

A família e a sua precária condição de vida são foco das falas dos vários entrevistados. Em relação a isso, a fonoaudióloga ressalta até que "jávieram denúncia que ela fica chorando de fome, ... que ela apanha, que a mãe e a avó fica sentada na calçada e que não dábola pra menina que tá chorando". Essa relação da criança com a família também é abordada pelo fisioterapeuta, que entende que entre elas "não tem vínculo.... Enum ésó de contato, de carinho. É de toda a dedicação também, da alimentação, da medicação. Eu acho que a Letícia é... muito mal cuidada, infelizmente". No entanto, para a assistente social, apesar de a família ter muito o que melhorar, "pro que era, já melhorou bastante".

Em função dessa forma de ver a criança e a família, algumas soluções foram apontadas ao longo do seguimento da criança. Nesse sentido, a psicóloga informa que "Atéqueriam levar ela pr'um hospitalem outra cidade, ela ia ficar internada, ia receber ... um amparo médico". Segundo a assistente social, o encaminhamento de Letícia ao hospital-lar não se concretizou por que "a instituição que o conselho estava negociando não aceitou. ... O Conselho Tutelarnão queria deixar definitivamente lá não épossível. É definitiva a internação. Então, resolveram investir mais na família". Em relação a esse encaminhamento, a psicóloga refere: "Tudo bem que ela precisa do carinho da família .... Mas, a mãe trabalha o dia todo .... Mas a vó entrou numa depressão pareceque muito séria, ....
Atéfalou de se matar, se perdesse a Letícia.... E a Lia, mãe dela, ficou com medo".

O conjunto desses aspectos acaba por influenciar o modo de ver as perspectivas futuras da criança. A psicóloga vê "possibilidade dela se desenvolver ... desdeque ela ... recebesse muito mais estímulo ... principalmente em casa". Já a assistente social refere: "Tirando o aspecto motor, de fala, se a família puder colaborar, ela vai conseguir. Precisava melhorar a moradia, a situação econômica, tudo isso afeta, né?"

Diante disso, os profissionais tratam da inclusão escolar e social de Letícia. A psicóloga afirma: "Que eu saiba, que ela (mãe) me fala, ela não tem nenhum contato ... não sai, não tem ... crianças pra brincar, não tem nada".

Quando indagada se chegou a ser conversado com a família sobre a frequência de Letícia a uma escola, primeiramente a psicóloga nem entende que a pesquisadora se referia a uma escola regular. Depois, sua fala indica que essa perspectiva não é considerada: "a Letícia. ... tá numa dificuldade ainda grande assim neurológica, não tá falando, não tá andando, nada". Na opinião do neurologista: "pra ela entrar numa escola normal, ela teria que ser uma escola muito adaptada".

\section{Discussão do caso de Letícia}

Acredita-se que, pelas características da criança e de sua família, dentre outros aspectos que marcam a situação, houve uma dificuldade de se falar de Letícia como pessoa. Fala-se da paralisia cerebral, do que pode ser feito no tratamento, das dificuldades com a família, mas praticamente nada se fala da criança. Outro aspecto de destaque é que, quando os profissionais exaltam alguma característica mais positiva da criança, em seguida se remetem a algo que explicita sua limitação.

Talvez a não aceitação de contato por parte da criança desempenhe importante influência nesse processo. Nas relações dialógicas, tal dificuldade causa no outro um distanciamento, suscitando sensação de impotência, fazendo com que o negativo se destaque.

Quanto à relação familiar, há concordância entre os profissionais no que diz respeito à quase negligência dessa família com relação à criança. Para os profissionais, o ambiente em casa é totalmente sem estímulo, e a criança não é sequer consolada ou atendida em suas 
necessidades básicas (limpeza, alimentação, uso da medicação, interação). A família, decerto, parece ter grande dificuldade em lidar com as limitações de Letícia, num contexto mais complexo ainda, em que estão em jogo questões como a própria subsistência do grupo familiar.

Percebe-se que, apesar do modo ambivalente, há uma grande identificação dos profissionais com a criança e uma vontade de proteger Letícia de tudo isso. Essas percepções, os posicionamentos e o abismo na comunicação influenciam o aqui e o agora e inclusive o olhar prospectivo dado para essa criança e sua família. A perspectiva possivelmente seja tão negativa que os profissionais, junto com o Conselho Tutelar, chegaram a pensar na retirada da criança da família.

Acredita-se que a impotência diante do sistema socioeconômico e cultural e a formação profissional em saúde centrada no indivíduo, visto de modo descontextualizado de seu meio, contribuam para guiar tal decisão, culminando na proposta de encaminhamento da criança ao hospital-lar.

É interessante notar que, na fala da psicóloga, há a exaltação da equipe de saúde dessa instituição que irá assistir Letícia continuamente, e não de forma intercalada e fragmentada como vem acontecendo. Tal postura baseia-se na ideia de que os pacientes devam se adaptar às proposições do campo da saúde e não que a saúde, para atuar de forma mais efetiva, deva estar junto à realidade do paciente. Não pode deixar de refletir ainda que, nesse encaminhamento a um hospital-lar, está implícita a ideia de um desenvolvimento que se dá linear e individualmente, de maneira descontextualizada, não havendo necessidade de que ele aconteça próximo aos familiares. Assim, a internação é valorizada, nem que isso implique a ruptura de vínculo com a família.

No entanto, a atuação em relação à criança é modificada, planejando-se um investimento na família, somente quando o hospital-lar não aceita a criança por um curto período de tempo. Paradoxalmente, a prioridade de Letícia é a instituição e a exclusão social da criança; quando a instituição se nega a aceitá-la, aí, sim, olha-se e pensa-se em como intervir junto à família.

Como citado acima, acredita-se que o desejo de proteger a criança permeie todo esse processo. Porém, não é só a criança que necessita de apoio e proteção, pois essa família também está totalmente desamparada e abandonada. Assim, nas dadas e complexas relações, vemos que ao mesmo tempo em que a criança constitui o outro como impotente, simultaneamente suscita nele o desejo de proteção diante do seu desamparo, buscando mesmo alternativas dramáticas. No caso, essas alternativas assumem grandes repercussões que extrapolam a atuação profissional, sendo isso possível em função do já discutido destaque que os profissionais de saúde têm na sociedade. O saber do campo da saúde tem, nesse contexto, dimensões importantes. Como afirma Foucault (2002), "não há saber que não suponha e não constitua ao mesmo tempo relações de poder", com esse destaque do saber do campo da saúde acabando por contribuir também para um aumento de poder.

Com relação às perspectivas futuras, indentificou-se a presença de opiniões que traduzem expectativas limitadas e pessimistas para a criança e para sua situação. Ressalta-se aqui a conturbada relação dessa família com os profissionais e a lacuna na sua comunicabilidade, fazendo com que também atribua-se à família uma significativa incompetência e tenha-se com ela uma total desesperança.

Finalmente, ao se pensar mais concretamente no processo de inclusão de Letícia, o que é realmente marcante é o fato de todos os profissionais acreditarem que ela não tenha nenhum convívio social. No entanto, esse anseio dos profissionais por uma maior participação social da criança é contraposto à sua participação escolar. Considerando todas as limitações da criança, da família e do sistema educacional, a inclusão escolar de Letícia é considerada unanimemente como impensável.

O que fica realmente explícita é a exclusão a que não só essa criança, mas sua família está submetida. Não há como pensar na inclusão de Letícia sem se remeter à exclusão da família. Há uma superposição de exclusões. Além da exclusão social associada aos aspectos orgânicos da criança, outras ligadas ao subemprego, à privação social e cultural e à possível perda da guarda da criança demonstram um processo atravessado e contraposto por situações de dialética exclusão/inclusão (Sawaia, 2002) da criança e de sua família no seio da realidade social. 


\section{Estudo de caso de Davi}

No caso de Davi, os profissionais que o atendiam à época eram o pediatra, duas fisioterapeutas e uma terapeuta ocupacional. Além desses, foram também entrevistados os profissionais do Núcleo de Saúde da Família (médico, enfermeira e assistente social) que haviam seguido Davi em seus dois primeiros anos de vida.

À época da coleta de dados, Davi tinha três anos e nove meses de idade. Desenvolveu o quadro de paralisia cerebral devido à anóxia perinatal. Decorrente disso, apresenta sequelas motoras mais evidentes nos membros inferiores. Havia aprendido a engatinhar há pouco tempo e não passava da posição deitada para sentada ou em pé. Quando sentado, permanecia com equilíbrio instável. Com esforço, alimentava-se sozinho e apresentava pouca dificuldade na manipulação de objetos. Ele é uma criança muito comunicativa, que demonstra e suscita satisfação no estabelecimento de contato. Adora conversar, contar histórias, tendo boa dicção, apesar de usualmente falar em um tom mais baixo que o habitual.

Davi mora com a mãe, o pai e o irmão. É filho único do casal, tendo mais dois outros irmãos de um primeiro casamento da mãe. Eles moram em uma pequena vila, localizada num bairro de uma cidade de médio porte do interior de São Paulo.

Como no caso de Letícia, será apresentado, primeiramente, o que foi dito pelos profissionais de saúde quando perguntado quem é e como é o Davi. Segundo a assistente social, "o Davi ... tem um deficit que épequeno". Diz ainda que ele "éuma criança muito meiga, muito alegre. Muito bem assistida". A médica do Núcleo de Saúde da Família corrobora, afirmando que "ele tem um olhar alegre, de uma criança feliz". Para a terapeuta ocupacional, "ele tem um cognitivo muito bom. ... a dificuldade motora ... num pode limitar esse desenvolvimento dele.... Eleéuma criança queémuito capazeécomo qualquer outra criança mesmo".

Quanto aos aspectos familiares, a assistente social refere que a mãe "... é uma pessoa muito inteira, ... ela cuida muito bem, ela é muito zelosa. Ela émuito preocupada em fazer todos os tratamentos possíveis, ela vaiatrás". A médica do Núcleo de Saúde da Família complementa: "A mãe corre muito atrás pra dar tudo aquilo que ele pode desenvolver. Se ele não pode desenvolver os 100\%, a família tá estimulando que ele desenvolva os 100\% queépossivel". Sobre o pai, a assistente social afirma que "ele bebia" e que "ele é muito afetivo com o filho".

Ao falar sobre o atendimento que é oferecido para o filho, a mãe afirma: "eles te mandam pro postinho, do postinho pro hospital, do hospital pra num sei onde. E se vocêfalta às consultas, ... vocênão está cuidando do seu filho. Evocêvai, vocêfalta emprego, patrão num quer saber". Complementa a mãe: "a gente querum lugar que a pessoa cuide e tudo seja discutido com ela que tá se responsabilizando pelo meu filho ... a gente possa se dirigir a ele pra saber oquefazer".

Essa fragmentação dos serviços também é tratada pelos profissionais. Dessa forma, a assistente social relata que "a mãetem quefazer umavia-cruzes pressemenino ser atendido, ... geralmente essas áreas trabalham de maneira muito desarticulada". Há na fala do pediatra uma mostra dessa desarticulação: "Serviço de puericultura e pediatria éo seguimento da criança, pesar, medir, ver as dificuldades que a mãe tem em relação à criança como um todo". Por outro lado, a área "motora, desenvolvimento, tudo fica mais a cargo do serviço terciário".

Diante desse quadro, os profissionais de saúde traçam perspectivas ao desenvolvimento futuro de Davi. A médica do Núcleo de Saúde da Família afirma: "aceitando as limitações, eu acho que o Davi tende a crescer muito... a gente tem que aprender a estimular aquilo que ele tem de bom, aquilo que ele pode desenvolver". A terapeuta ocupacional também acredita no bom desenvolvimento de Davi: "ele vai ter uma autonomia muito grande, sendo livre pra poder tá fazendo as coisas sozinho, dentro daquele limite dele... . a parte de atividades da vida diária ou mesmo de alguma atividade profissional que ele venha, no futuro, a tá conseguindo fazer".

Com relação ao processo de inclusão escolar de Davi, é importante ressaltar que ele estava próximo de completar quatro anos de idade e isso traria algumas mudanças em sua rotina. A criança fazia acompanhamento de fisioterapia e terapia ocupacional em um centro de estimulação precoce, que trabalha com crianças até elas completarem quatro anos. A partir daí, elas são encaminhadas para outros serviços de saúde e/ou para a rede regular de ensino. No caso de Davi, as terapeutas estavam orientando a mãe a procurar uma escola regular próxima à sua casa. Como relata a fisiote- 
rapeuta, "Porque o Davijá completou quatro anos, ... elejá entraria ... na escola. Conversamos com ela (mãe) como que ela tinha que fazer". Para essa mudança de serviço, a fisioterapeuta informa, ainda, que "a gente num faz o encaminhamento por escrito, pra dizer "a criança tem... paralisia cerebral" ..., porque isso ... em vez de facilitar, ia prejudicar". Nesse sentido, a terapeuta ocupacional afirma: "nós que puxamos ela pra ela poder tá procurando essa escola.... Eela fez tudo direitinho. Talvez atéo ano que vem ele vájámesmo pra escola".

\section{Discussão do caso de Davi}

No caso de Davi, percebe-se como unânime a satisfação em lidar com a criança, o que foi também sentido pela pesquisadora quando da visita domiciliar. E, no jogo dinâmico de figura-fundo, a paralisia cerebral aparece apenas como mais um elemento que o constitui, em muitos momentos chegando mesmo a ficar em um segundo plano. Além dessas capacidades de interação, a sua capacidade cognitiva é muito exaltada, sendo compreendida como um importante facilitador nas relações e nos processos que envolvem seu cuidado e tratamento.

$\mathrm{Na}$ fala dos profissionais, no rol de aspectos positivos da criança, aparece o destaque em relação ao papel da família, em especial o da mãe. A mãe cuida, busca desenvolver os "100\% possíveis" do desenvolvimento de Davi. O pai parece não ser tão visível e presente como a mãe nos seguimentos de Davi. Porém, ele é citado como alguém que tem afeto pelo filho e quer lutar por seu tratamento, apesar de suas dificuldades, particularmente o alcoolismo.

Muito provavelmente, além do empenho da mãe, é a credibilidade depositada por ela no serviço de saúde que a alça a um lugar especial dentro desse serviço. E esse seu papel ativo leva a que seja tratada com respeito por todos os profissionais de saúde. É nessa interação entre a família e o serviço de saúde que se dá o modo de construção da relação e de tratamento destinado a essa criança. Apresenta-se, assim, uma parceria entre eles. Não é o Davi que tem um problema e deve aprender a lidar com ele. O problema é deles - mãe e criança - e a solução deve ser encontrada conjuntamente (Roriz, 2005).

Com relação aos atendimentos de saúde, a multiplicidade de organizações, condições, vozes e sentidos é imensa. Nessa multiplicidade, desamparada, a família se dispersa; encontra-se perdida e dividida dentro de um sistema em que o governo não assume integralmente a responsabilidade pelo atendimento à saúde da população. Assim, o sistema de saúde a que tem acesso é fragmentado, sendo composto por diferentes ordens de serviço - fundamentalmente o privado e o público. Esse último encontra-se organizado em três níveis - primário, secundário e terciário - que, na prática, ao invés de articularem a intervenção em torno dos pacientes de acordo com suas necessidades, de maneira geral, assumem burocraticamente e de modo desarticulado a sua função. Nesse serviço de saúde fragmentado, a família fica à mercê das mais diferentes orientações, sem que ninguém assuma a responsabilidade pelos procedimentos.

Percebe-se, ainda, que a formação profissional circunscreve condutas, mas essas não são naturalizadas e circunscritas unicamente por essa formação, sendo permeadas também pelo contexto de trabalho de cada um, pelo lugar e pela posição de onde cada um fala. Dessa forma, o modo como cada serviço se estrutura contribui para circunscrever muitas das condutas ali assumidas e para criar ou não espaços para certas práticas. Exemplo disso é a explicação do pediatra sobre o que vem a ser um serviço de pediatria e puericultura: .... Éo seguimento da criança, pesar, medir",já "a área... motora, desenvolvimento... tudo fica mais a cargo do serviço terciário". Isso deixa explícita uma prática fragmentada, com uma visão pontual do paciente. O que se vê é que a atuação de cada profissional é entendida como múltipla, atravessada e constituída por aspectos do contexto, da formação, do local de trabalho, da relação com a criança, com a família, dentre outros.

Dentro desse quadro, traçam-se perspectivas ao desenvolvimento futuro de Davi. Nesse sentido, percebe-se, no discurso dos profissionais, que a criança está presente como pessoa, sendo vista muito além de sua patologia, o que lhes permite antevê-la como capaz de alcançar autonomia até mesmo no âmbito profissional, distanciando-se da situação de dependência e improdutividade. Mesmo que as limitações sejam reconhecidas e destacadas, elas não capturam os profissionais e aprisionam o seu olhar.

É a partir desses olhares que os processos de inclusão são concebidos para Davi. Observa-se uma 
intenção de garantir sua inclusão escolar, apesar de que o procedimento que se faz é extremamente burocratizado e visa, em grande medida, o próprio fluxo da instituição. Assim, o encaminhamento do serviço de saúde à escola se faz relacionado à idade da criança, sendo essa transferência feita de modo automático.

Os limites da educação inclusiva, no entanto, são denunciados na fala da fisioterapeuta que alega que, para que a vaga da criança seja garantida, é melhor que a família não diga que se trata de uma criança com deficiência. Porém, se pensarmos em quem a está recebendo - a escola - e se realmente existe algo contra essa inclusão, tal medida pode, em vez de promover a articulação dos serviços e da inclusão da criança, gerar uma reação de surpresa e incômodo.

\section{Discussão}

Pelo entrelaçamento das diversas falas, observa-se uma série de aspectos que merecem um aprofundamento na discussão. No que se refere ao papel dos profissionais no processo de inclusão, de maneira genérica, há uma sensação geral de impotência e algumas vezes de descompromisso, tendo em vista que o processo envolve outros elementos com relação aos quais eles não sabem como lidar, como a pobreza, por exemplo. Isso faz com que a inclusão seja usualmente pensada mais estritamente a partir dos referenciais de conhecimento e atuação do profissional, da especialidade e do próprio serviço. Além disso, o foco é centrado, quase que exclusivamente, na criança, primando o atendimento ao indivíduo, que, usualmente, évisto de forma quase que totalmente descontextualizada da situação em que vive.

Essas particularidades - e mesmo as dificuldades de olhar e discutir o processo de inclusão - provavelmente derivam do fato de que pensar nessa premissa impõe necessariamente considerar a pessoa integralmente em sua relação com o meio. Isso é quase impossibilitado quando se considera a criança de modo parcial, centrada na deficiência, fragmentada, dicotomizada do seu ambiente.

No entanto, os dados revelaram que não é só a formação do profissional que contribui para essa forma de abordar o paciente e o problema. Observa-se também que a forma de organização de cada serviço de saúde nitidamente proporciona oportunidades e práticas discursivas distintas dos profissionais que fazem parte do serviço.

O olhar para a criança com deficiência é atravessado por todos esses aspectos. A posição, o lugar de quem fala, o contexto específico da situação no aqui e agora, as metas, as expectativas e cada elemento trazem ideias e delimitam posturas e significados diversos. Como Foucault (2003) afirma, "há uma multiplicidade de elementos discursivos que podem entrar em estratégias diferentes. Supõe-se variantes e efeitos diferentes segundo quem fala, sua posição de poder, o contexto institucional em que se encontra".

Ao considerar os dois casos, questões bastante diversas emergem e revelam diferentes facetas do mesmo processo, que serão abordadas a seguir separadamente, mas devendo-se ter claro que elas não estão desvinculadas, mas intrinsecamente articuladas umas às outras.

Quando se analisa a forma como cada criança é vista, verifica-se que é bem diversa nos dois casos. Letícia quase não é visualizada como pessoa; já com Davi ocorre o oposto. Em cada caso, esse olhar leva à possibilidade de ver ou não além da própria deficiência.

Algo que também merece ser ressaltado é o aspecto da cognição, atribuída e exaltada em Davi e entendida como ausente em Letícia. E, ainda, a presença de verbalização em Davi, aspecto bastante valorizado em nossa sociedade. Esses elementos vão circunscrevendo as concepções e a atuação de cada profissional e de suas perspectivas com relação ao desenvolvimento futuro dessas crianças. No caso de Davi, criam-se expectativas inclusive voltadas a uma vida profissional; para Letícia, impõem-se perspectivas muito restritas de que ela venha a se desenvolver minimamente.

Com relação às famílias e às possibilidades que elas podem oferecer ao desenvolvimento da criança com necessidades especiais e à inclusão, as práticas discursivas dos profissionais mostram-se também podendo ser bastante diferentes. Dadas as características de cada família, elas vão ser consideradas como competentes ou incompetentes para criar e educar seu próprio filho, e a relação vai ser fortemente constituída em função do lugar que a família coloca o serviço de saúde, com repercussões na relação e valorização do grupo familiar. No caso de Letícia, a família é vista como 
alheia e incapaz. No caso de Davi, totalmente capaz, inclusive por que a família fala e lida com a situação imersa no campo da saúde (Roriz, 2005). No primeiro caso, a família acaba por ser tutelada pela APAE e pelo Conselho Tutelar; no outro, destaca-se a busca pela independência.

No caso de Davi, faz-se necessário um empenho redobrado, por parte da família, para garantir a sua ida a todos os tratamentos, que ocorrem em locais distintos. Não apenas há dificuldade de ingressar em novos serviços, como também, em função das normatizações dos serviços, há a ocorrência do desligamento de instituições em que a criança já estava inserida.

O que se vê é que quando a família tem uma maior estrutura social, econômica e cultural, por conta própria ela vai à luta da forma que lhe é possível. No entanto, tal situação se mostra agravada no caso de famílias que não contam com tal estrutura, como é o caso da família de Letícia. Nesse caso, no rol de diagnósticos quanto a incapacidades, a família é julgada também como deficiente - precisando ser assessorada -, o que nessa situação específica leva inclusive ao risco de perda da guarda da criança.

A falta de estrutura e suporte social do Estado se desloca assim para a família, e os serviços de saúde e entidades governamentais, na mesma linha identificada na revisão bibliográfica (Roriz et al., 2005), ouvem pouco as pessoas com necessidades especiais, atuando com elas, segundo seus próprios princípios e concepções (Abrantes-Pego, 1999, Cook, Swain \& French, 2001). Isso não significa que não haja resistências por parte dos que não estão sendo ouvidos. As distribuições de poder e as apropriações de saber são matrizes de transformações, como refere Foucault (2003).

Nos dois casos, a impotência dos profissionais de saúde emerge de forma intensa. No caso de Letícia, pelas dificuldades da criança e da família, além das múltiplas exclusões a que elas estão colocadas. A sensação de impotência é tamanha que gera a possibilidade da perda de guarda por parte da família. No caso de Davi, há empatia pela criança e pela família, e identificam-se as dificuldades com que a luta pelo atendimento de saúde acontece. A impotência aparece pela possibilidade de fazer somente uma ação mais pontual, mais localizada.

Como marca, nos dois casos, está a questão da

340 fragmentação, que aparece na maneira de olhar a pessoa, que se dá de forma descontextualizada e a partir de funções, órgãos e atividades profissionais. Mas também tal fragmentação pode ser vista na desarticulação dos profissionais dentro de uma mesma equipe, de um mesmo serviço. Ou, ainda, dentro de diferentes tipos de serviço. Essa fragmentação coloca a pessoa sem uma referência com relação ao seguimento da criança, que percorre uma enormidade de atendimentos, profissionais, locais de serviços, sem que haja alguém que assuma de fato a responsabilidade pelo caso e que articule as diferentes atividades e profissionais, considerando as necessidades da família e da criança.

Finalmente, atravessando todos os contextos, percebemos grandes limitações nas instituições, fazendo com que limites rígidos aos atendimentos sejam estabelecidos (como um recorte por idade). Daí a responsabilidade ser transferida para a escola. Porém, como Yazlle (2001) verificou, nessa mesma região, a escola também não se encontra preparada para atender e dar conta dessa demanda. Isso coloca a família numa lacuna, num limbo em que nem uma instituição e nem outra dá apoio de fato ao desenvolvimento da criança e sua família.

\section{Considerações Finais}

Pela análise dos casos investigados, pôde-se ter uma amostra da imensa complexidade e das contradições que envolvem as práticas discursivas no processo de inclusão/exclusão de criança com deficiência. Mais especificamente, tomando-se como referência os profissionais de saúde, conhecemos algumas das múltiplas questões que contribuem para circunscrever suas percepções, expectativas e atuações, que são atravessadas por diversos aspectos, os quais envolvem as características da criança, a organização da família, a formação acadêmica e o contexto profissional, dentre outros.

Verificou-se, também, as incertezas que atravessam o campo de saúde de maneira tão maciça, podendo inclusive paralisar os profissionais. Algumas daquelas incertezas inclusive antecedem os questionamentos sobre a concreta prática do processo de inclusão de crianças com necessidades especiais. As incertezas englobam ainda questões como: o que são necessidades especiais? No que implica incluir pessoas com necessidades especiais? É o momento para isso? $\mathrm{E}$, ainda, qual o papel do profissional de saúde nesse processo? 
Para finalizar, é importante destacar que, quando situado o presente trabalho dentro da revisão bibliográfica nacional e internacional, ele revela sua novidade no campo. Porém, é justamente a novidade e a escassez de uma discussão mais direta sobre o tema que nos impuseram a estratégia de pesquisa, que busca apreender elementos da situação a partir de um estudo exploratório. Diante disso, foi feita a opção pela realização de estudos de caso (Yin, 2005).

Buscou-se adentrar na complexidade da situação e que este estudo representa uma abordagem inicial ao tema. Apesar dos resultados, não permitirem uma generalização estatística, dão indícios e pistas para apontar algumas questões de ordem teórico-práticas.

Dessa forma, a partir das vozes e práticas discursivas identificadas nos estudos de caso, a presente pesquisa aponta na direção de alguns aspectos que devam ser mais aprofundados em trabalhos futuros. Pensar ainda na inclusão e na educação inclusiva de crianças com deficiência nos remete a aspectos que vão muito além da formação do educador, do pedagogo. Nesse sentido, as falas indicam a necessidade de se refletir e re-estruturar mesmo a formação dos profissionais de saúde, perspectiva que implica uma posição político-ideológica que extrapola em muito o escopo deste trabalho.

O trabalho de investigação sobre a óptica dos profissionais de saúde faz emergir questões em relação às concepções e significações do processo inclusivo de crianças deficientes que podem ser abordadas no processo de graduação dos profissionais de saúde. Ao se considerar a óptica dos profissionais, o que se coloca é a necessidade de um novo olhar a ser lançado por eles, com o qual a psicologia tem a possibilidade de contribuir.

\section{Referências}

Abrantes-Pego, R. (1999). Participación social en salud: um estudio de caso en Brasil. Salud Publica de México, 41 (6), 466-474.

Amorim, K. S. (2002). Concretização de discursos e práticas histórico-sociais, em situações de freqüência de bebês a creche. Tese de doutorado não-publicada, Universidade de São Paulo, Ribeirão Preto.

Baker, K., \& Donelly, M. (2001). The social experiences of children with disability and the influence of environment: a framework for intervention. Disability and Society, 16 (1), 71-85.

Cook, T., Swain, J., \& French, S. (2001). Voices from segregated schooling: towards an inclusive education system. Disability and Society, 16 (2), 293-310.

Foucault, M. (2002). Vigiar e punir (26a ed.) Petrópolis: Vozes.

Foucault, M. (2003). História da sexualidade: a vontade de saber (15 ed.) Rio de Janeiro: Graal.

Jannuzzi, G. S. M. (2004). A educação do deficiente no Brasil: dos primórdios ao início do século XXI. Campinas: Autores Associados.

Lebeer J, \& Rijke R. (2003) Ecology of development in children with brain impairment. Child: Care, Health and Development, 29 (2),131-40.

Parmenter, T. (2001). The contribution of science in facilitating the inclusion of people with intellectual disability into the community. Journal of Intellectual Disability Research, 45 (3), 183-193.

Rao, S. (2001). 'A little inconvenience': perspectives of Bengali families of children with disabilities on labelling and inclusion. Disability and Society, 16 (4), 531-548.

Roriz, T.M. (2005). Inclusão/exclusão social e escolar de crianças com Paralisia Cerebral, sob a óptica dos profissionais de saúde. Dissertação de mestrado não-publicada, Universidade de São Paulo, Ribeirão Preto.

Roriz, T. M., Amorim, K. S., \& Rossetti-Ferreira, M. C. (2005). Inclusão social/escolar de pessoas com necessidades especiais: múltiplas perspectivas e controversas práticas discursivas. Revista de Psicologia - USP, 16 (3), 167-194.

Rossetti-Ferreira, M. C., Amorim, K. S., \& Silva, A. P. S. (2000). Uma perspectiva teórico-metodológica para análise do desenvolvimento humano e do processo de investigação. Psicologia: Reflexão e Crítica, 13 (2), 281-293.

Rossetti-Ferreira, M. C., Amorim, K. S., Silva, A. P. S., \& Carvalho, A. M. A. (Orgs.) (2004). Rede de significações e o estudo do desenvolvimento humano. Porto Alegre: Artmed.

Sawaia, B. (Org.) (2002). As artimanhas da exclusão: análise psicossocial e ética da desigualdade social (4a ed.) Petrópolis: Vozes.

Spink, M. J. P. (Org.) (1999). Práticas discursivas e produção de sentidos no cotidiano: aproximações téoricas e metodológicas. São Paulo: Cortez

Spink, M. J.P. (2003) Psicologia social e saúde: práticas, saberes e sentidos. Petrópolis: Vozes.

Yazlle, C. (2001). Pré-escolas convivendo com a paralisia cerebral: uma análise do processo de inclusão/exclusão. Dissertação de mestrado não-publicada, Universidade de São Paulo, Ribeirão Preto.

Yin, R. K. (2005) Estudo de caso: planejamento e métodos (3a ed.) Porto Alegre: Bookman.

Recebido em: 3/3/2008

Versão final reapresentada em: 10/12/2008

Aprovado em: 26/5/2009 
Roteiro da entrevista com os profissionais

1) Para você, quando uma pessoa é vista como portadora de necessidades especiais?

2) E o que você entende por inclusão?

3) Como é a (o) * ?

4) Você sabe como ele (a) é tratada e cuidada, no ambiente doméstico?

5) Tem alguma ideia de como ele (a) participa dos e nos diferentes contextos sociais (família, vizinhança, clínica...)?

6) Para você, quais os aspectos com relação a ele (a) que são vistos como facilitadores ou como limitadores do processo de inclusão?

7) Alguma vez foi conversado com a família sobre a colocação ou não de * na escola? Se já estiver na escola: Quando a família pensou em colocá-lo (a) na escola vocês conversaram?

8) Quais as suas perspectivas com relação ao desenvolvimento futuro dessa criança?

9) Quais as maneiras de atuar, com o objetivo de promover a inclusão de * na sociedade?

${ }^{*}$ Criança

ANEXO 2

Roteiro da entrevista com as famílias

1) Conte-me um pouco sobre a história do(a)

2) Como é o dia dele(a)? O que ele(a) faz?

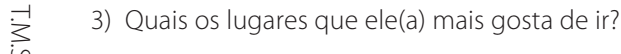

4) Que tipo de atividades ele(a) gosta de fazer fora de casa?

5) Como é o comportamento dele(a) nos lugares?

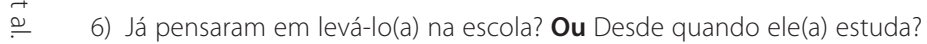

7) O que as pessoas (parentes/amigos), os professores ou os profissionais de saúde pensam sobre isso?

342

8) Se estuda: Como foi quando ele(a) começou a estudar? 